\title{
Combining Cryptography with Steganography
}

\author{
Muharrem Tuncay GENÇOĞLU*
}

Vocational School of Technical Sciences, Firat University, Elazig, Turkey

\begin{abstract}
In this paper a different cryptographic method is introduced by using Power series transform, codes of ASCII and science of steganography. Here,we produce a new algorithm for cryptology,we use Expanded Laplace transformation of the exponential function for encrypting the plain text and we use codes of ASCII for support to the confidentiality of the chipertext. After, Chipertext have embedded by steganographic method in another plaintext to hide the existence of chipertext. We show corresponding inverse of Power Series transform for decryption.
\end{abstract}

Key words: Cryptology, Encryption, Decryption, Laplace Transform, ASCII, Steganography.

* Corresponding author: mtgencoglu23@gmail.com 


\section{Introduction}

Foundation based on ancient the confidential communication,with the technological progress it has varied in terms of form and methods, have maintaned continuous its importance. To be very important of privacy in applications; protected information before hand of third parties were aimed to sending related destination and studies in this direction were made [2-6-7]. Network security problem has become very important in recent years. E-banking, e-commerce, e-government, e-mail, SMS services, security of ATMs, the existence of financial information has become indispensable in our lives. In these environments the processed and transferred to the protection of information or to ensure safety is of great importance. The Digital environment while providing data communication, from the sender to the recipient data unauthorized access, damage, prevent as there are many threats. These threats for the elimination of many encryption technique improved[2,6-9]. Cryptography is the all of mathematical technical studies related to information security. Cryptology is cipher science and ensures security of information.

The main goal of cryptography is to allow two people to communicate through non-secure channels. Encryption is the process of blocking information to make it unreadable without special knowledge. These operations are expressed using an algorithm. In general this is called the symmetric algorithms. For encryption and decryption must be used the same secret key in the symmetric algorithms[5]. The converse is also true. The security of this algorithms is associated with key[2]. The original information is known as plain text and cryptic text is encrypted format of this text. Encrypted text message contains all of the information in plain text message but It is not a readable format by a human or a computer without a suitable mechanism to decryption. The cipher is expressed by the parameters often called as the key by part of the external information. Encryption procedure is changed to vary of details of the algorithm operation based on the key. Without an appropriate key decryption is almost impossible. Advanced Encryption Standard (AES) method is the most used. Figure-1 also shows a symmetrical crypto system $[2,7,8,9,10,11]$. Steganography is come into question to hide a text as a complementary security solution at this point. Steganography as word meaning means hidden text or covered text.It is art of storing information which can not be detected the presence[10]. The objective of the Steganography is hide the presence of a message and is create a channel to the implicit [11].

In this study; steganography and cryptrography using together is intented to increase security for confidential data.Power series are used for cryptography. This process has been supported with 8 bit ASCII code and a high security application has been implemented for confidential data with steganography combined. In the second section of the study;Respectively definations and some standard results are given for the proposed method.In the third section,flow diagrams are given together with recommended method and practice. In the fourth section, the evaluation of the results from the study are situated.

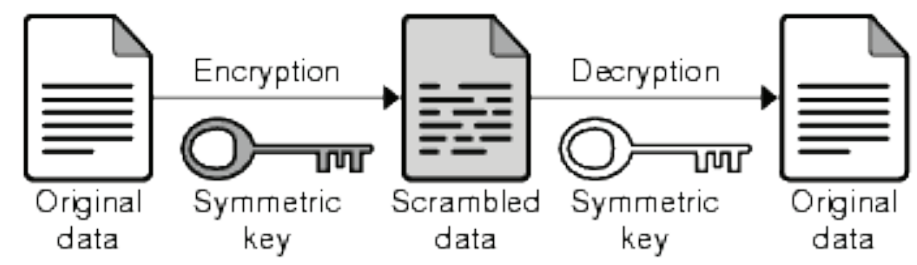

Figure 1.

\section{Preliminaries}

\subsection{Definition}

Let $f(t)$ be defined for $t>0$. We say $f$ is of exponential order if there exist numbers $\alpha, M>0$ so that

$$
|f(t)| \leq M e^{\propto t}
$$


If $f(t)$ is exponential function then we have $f(t)=\infty$ for $t \rightarrow \infty[1]$.

\subsection{Definition}

Let $f(t)$ be given for $t \geq 0$ and assume the function satisfy the property of $\alpha$ exponential order and $t, s \in R$. The Laplace transform of $\mathrm{f}(\mathrm{t})$ is defined by [1]

$$
F(s)=\int_{0}^{\infty} e^{-s t} f(t) d t
$$

Lets define a new transformation function by expanding the Laplace transformation using Definitions 1 and 2.

\subsection{Definition}

Transformation of $\mathrm{f}(\mathrm{t})$ for every $\mathrm{t} \geq 0$ is defined as:

$$
F(h)=T[f(t)]=\int_{0}^{\infty} \frac{1}{h} e^{\frac{-t}{h}} f(t) d t .
$$

(Extended Power Series Transformation) We present $f(t)=T^{-1}[F(h)]$ to define the inverse transformation of $f(t)$. Obtained extended power series transformation has the following standard results $[3,4]$

$$
\begin{gathered}
1 . T\left\{t^{n}\right\}=\frac{n !}{s^{n+1}} \Rightarrow T^{-1}\left\{\frac{1}{s^{n+1}}\right\}=\frac{t^{n}}{n !} \\
2 . T\left\{t^{n} e^{s t}\right\}=\frac{n ! \cdot h^{n}}{(1-s h)^{n+1}} \Rightarrow \quad T^{-1}\left\{\frac{h^{n}}{(1-s h)^{n+1}}\right\}=\frac{t^{n} \cdot e^{s t}}{n !} \quad(\mathrm{t} \geq 0)
\end{gathered}
$$

\subsection{Definition}

In order to keep the text information in the computer memory computer system assigns a numerical value to each letter or symbol. This process depends on the encoding system. By setting the numerical value of symbols, in order to represent non-numeric or alphabetic type of information on the computer the most commonly used as the coding system is used in ASCII coding system [4].

\subsection{Definition}

The process of fitting a data or message into another object is called steganography. The goal is to conceal the existence of the message [6].

\section{Application}

By combining methods of cryptography and steganography application stages of this hybrid model that increases data security and privacy are as follows;

\subsection{Encryption} $e^{t}$

Assume that we want to send the message "FIRAT". Firstly we consider extended Taylor series with

$$
\begin{gathered}
f(x)=f(a)+\frac{f^{\prime}(a)}{1 !}(x-a)+\frac{f^{\prime \prime}(a)}{2 !}(x-a)^{2}+\cdots+\frac{f^{n}(a)}{n !}(x-a)^{\mathrm{n}}+\cdots \\
=\sum_{n=0}^{\infty} \frac{f^{n}(a)}{n !}(x-a)^{\mathrm{n}} .
\end{gathered}
$$

Then, if we expand; 


$$
e^{t}=1+\frac{t}{1 !}+\frac{t^{2}}{2 !}+\frac{t^{3}}{3 !}+\cdots=\sum_{n=0}^{\infty} \frac{t^{n}}{n !}
$$

with $\mathrm{t}^{3}$, then we get:

$$
t^{3} e^{t}=t^{3}+\frac{t^{4}}{1 !}+\frac{t^{5}}{2 !}+\frac{t^{6}}{3 !}+\cdots=\sum_{n=0}^{\infty} \frac{t^{n+3}}{n !}
$$

Therefore, we obtain:

$$
f(t)=\sum_{n=0}^{\infty} K_{n} \frac{t^{n+3}}{n !} .
$$

If we enumarate letters of the alphabet from scratch "FIRAT" plain text be equal 6,9,19,0,22. If we write $\mathrm{K}_{0}=6, \mathrm{~K}_{1}=9, \mathrm{~K}_{2}=19, \mathrm{~K}_{3}=0, \mathrm{~K}_{4}=22$ in to (3.4), we get

$$
\begin{aligned}
& f(t)=\sum_{n=0}^{\infty} K_{n} \frac{t^{n+3}}{n !} \\
&=K_{0} \frac{t^{3}}{0 !}+K_{1} \frac{t^{4}}{1 !}+K_{2} \frac{t^{5}}{2 !}+K_{3} \frac{t^{6}}{3 !}+K_{4} \frac{t^{7}}{4 !}
\end{aligned}
$$

If we apply extended power series transformation to both sides of (3.5), we get

$$
\begin{gathered}
T[f(t)](h)=T\left[\sum_{n=0}^{\infty} K_{n} \frac{t^{n+3}}{n !}\right](h) \\
=T\left[K_{0} \frac{t^{3}}{0 !}+K_{1} \frac{t^{4}}{1 !}+K_{2} \frac{t^{5}}{2 !}+K_{3} \frac{t^{6}}{3 !}+K_{4} \frac{t^{7}}{4 !}\right](h) \\
=6.3 ! h^{3}+9.4 ! h^{4}+19.5 ! \frac{h^{5}}{2 !}+0.6 ! \frac{h^{6}}{3 !}+22.7 ! \frac{h^{7}}{4 !} \\
\sum_{n=0}^{\infty} K_{n}(n+3) ! \frac{h^{n+3}}{n !}=36 h^{3}+216 h^{4}+1140 \frac{h^{5}}{2 !}+0 \frac{h^{6}}{3 !}+4620 \frac{h^{7}}{4 !} .
\end{gathered}
$$

The provisions of $36,216,1140,0,4620$ in the modes $(28)$ are $\left(K_{n}\right) 8,20,20,0,0$. If we write quotient in mode operation instead of these numbers, we obtain the key $\left(K_{n}^{\prime}\right) 1,7,40,0,165$. "FIRAT" plain text converts "HSSAA" by (3.3).

If we convert "HSSAA" encrypted text to 8-bit characters in the ASCII code we obtain 72,83,83,65,65. If these codes are written in binary system we get the keys $(1001000)_{2},(1010001)_{2},(1010001)_{2},(1000001)_{2}$, $(1000001)_{2}$. ASCII 8 bit keys are in the text as follows: A provision giving the binary number system in the space between each word of the text namely if the number between two words 1 then we get (1) $)_{2}$ and we define 2 with $(0)_{2}$.

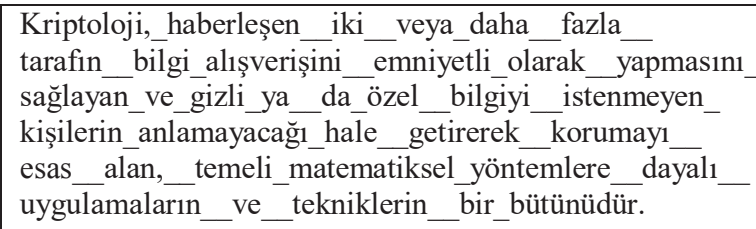

Cryptology is a set of practices and techniques based on the basis of mathematical methods providing safety of the exchange of information communicating two or more the parties and bringing protection to make people to not understand unsolicited confidential or proprietary information.

Table 1. Embedded Text

Sender also send this text clearly with $(1,7,40,0,165)$ secret key.

Hence theorem can be following 


\subsubsection{Theorem}

The given plain text in terms of $\left(K_{n}\right)$, under Laplace transform of $K_{n} \frac{t^{n+3}}{n !}(h)$, can be converted to cipher text,

$$
\left(K_{n}^{\prime}\right)=\left(K_{n}\right)-28 q_{n} \quad(\mathrm{n}=0,1,2, \ldots)
$$

Where a key

$$
q_{n}=\frac{K_{n}-K_{n}^{\prime}}{28} \quad(\mathrm{n}=0,1,2, \ldots)
$$

\subsection{Decryption}

The recipient receives a text message and by reading the spaces between words with software that will get the data buried create the necessary numerical equivalents. If these numbers are divided into 8-bits groups then ASCII provision of the data buried has been obtained. We can see the hidden data buried "HSSAA" in the Table 2.

Kriptoloji,_haberleşen_iki_veya_daha_fazla_ tarafin_bilgi_alışverişini__emniyetli_olarak_yapmasını sağlayan_ve_gizli_ya_da_özel_bilgiyi_istenmeyen_ kişilerin_anlamayacağı_hale_getirerek_korumayı esas_alan,_temeli_matematiksel_yöntemlere_dayalı uygulamaların ve tekniklerin bir bütünüdür.

\begin{tabular}{|c|c|c|c|c|c|}
\hline Text Bits & 100 & 101 & 101 & 100 & 100 \\
& 1000 & 0001 & 0001 & 0001 & 0001 \\
\hline Hidden Data & 72 & 83 & 83 & 65 & 65 \\
\hline Encryption Message & $\mathrm{H}$ & $\mathrm{S}$ & $\mathrm{S}$ & $\mathrm{A}$ & $\mathrm{A}$ \\
\hline
\end{tabular}

Table 2. Embedded text and solution

If we write $\mathrm{H}, \mathrm{S}, \mathrm{S}, \mathrm{A}, \mathrm{A} \rightarrow 8,20,20,0,0$ and secret key values $(1,7,40,0,0,165)$ into

$$
A_{n}=\frac{K_{n}-K_{n}^{\prime}}{28}
$$

$36=28 x 1+8$

$\mathbf{2 1 6}=28 \times 7+20$

$1140=28 x 40+20$

$\mathbf{0}=28 x 0+0$

$4620=28 \times 165+0$ are obtained.

If we apply these values $36,216,1140,0,4620$ to the

$$
\sum_{n=0}^{\infty} K_{n}(n+3) ! \frac{h^{n+3}}{n !}
$$

then, we get 


$$
\begin{gathered}
\sum_{n=0}^{\infty} K_{n}(n+3) ! \frac{h^{n+3}}{n !}=36 h^{3}+216 h^{4}+1140 \frac{h^{5}}{2 !}+0 \frac{h^{6}}{3 !}+4620 \frac{h^{7}}{4 !} \\
=6.3 ! h^{3}+9.4 ! h^{4}+19.5 ! \frac{h^{5}}{2 !}+0.6 ! \frac{h^{6}}{3 !}+22.7 ! \frac{h^{7}}{4 !}
\end{gathered}
$$

If we apply inverse Extended Power Series Transformation to both sides of the (3.7), then we get

$$
\begin{gathered}
T^{-1}\left[\sum_{n=0}^{\infty} K_{n}(n+3) ! \frac{h^{n+3}}{n !}\right]=T^{-1}\left[6.3 ! h^{3}+9.4 ! h^{4}+19.5 ! \frac{h^{5}}{2 !}+0.6 ! \frac{h^{6}}{3 !}+22.7 ! \frac{h^{7}}{4 !}\right] \\
\sum_{n=0}^{\infty} K_{n} \frac{t^{n+3}}{n !}=6 . t^{3}+9 . t^{4}+19 \cdot \frac{t^{5}}{2 !}+0 \cdot \frac{t^{6}}{3 !}+22 \cdot \frac{t^{7}}{4 !}
\end{gathered}
$$

If we convert the $K_{n}$ coefficients we will get the first plain text $6,9,19,0,22 \rightarrow \mathrm{F}, \mathrm{I}, \mathrm{R}, \mathrm{A}, \mathrm{T}$.

Hence theorem can be following

\subsubsection{Theorem}

The given cipher text in terms of $\left(K_{n}^{\prime}\right)$, with a given key $q_{n}$, can be converted top lain text $\left(K_{n}\right)$ under the inverse Laplace transform of

$$
T^{-1}\left[\sum_{n=0}^{\infty} K_{n}(n+3) ! \frac{h^{n+3}}{n !}\right]=\sum_{n=0}^{\infty} K_{n} \frac{t^{n+3}}{n !}
$$

Where

$K_{n}=28 q_{n}+K_{n}^{\prime} \quad(\mathrm{n}=0,1,2, \ldots)$.

Operations performed in this section is shown in Figure 2 and Figure 3. 


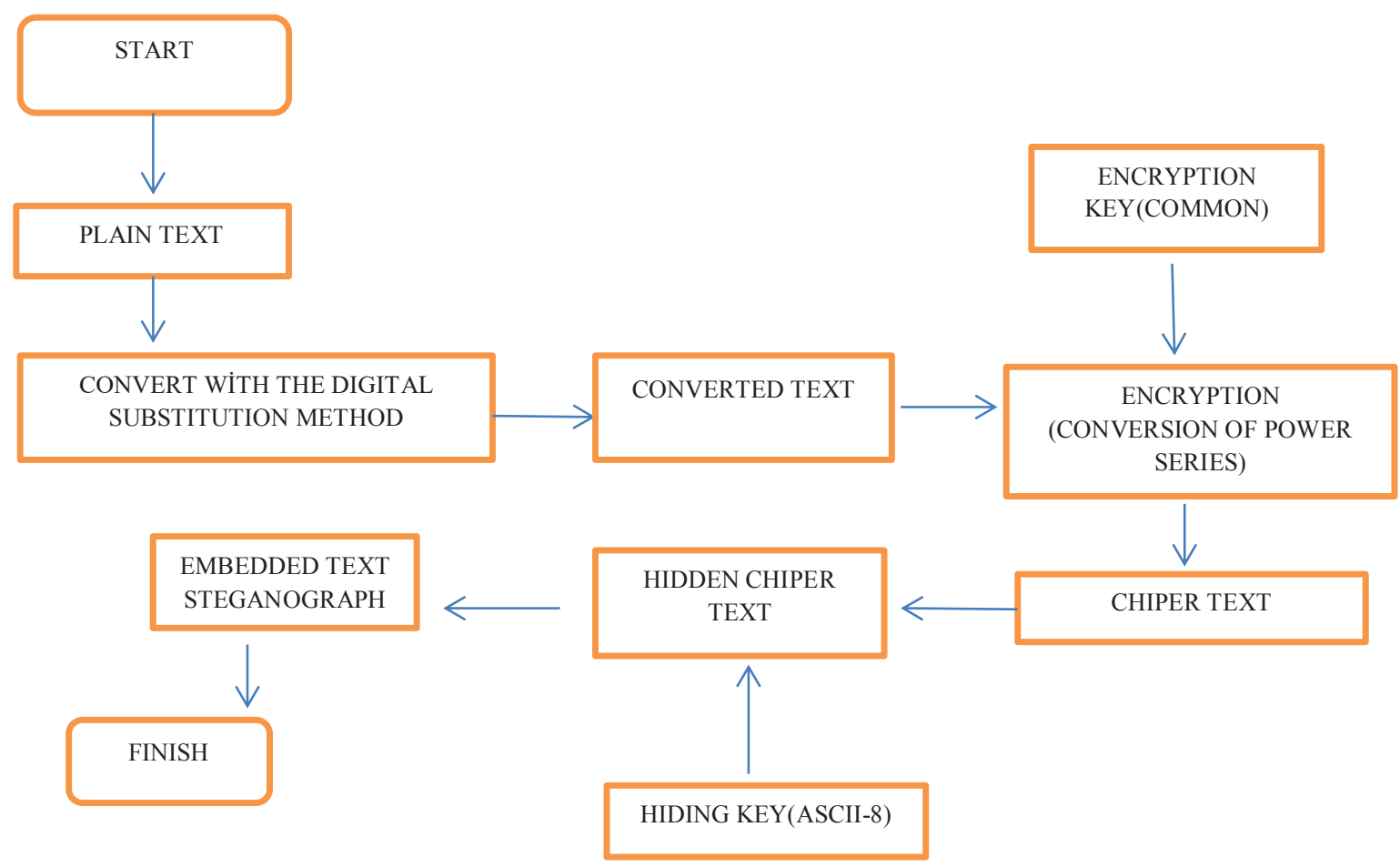

Fig. 2. Flow Diagram of Encryption System

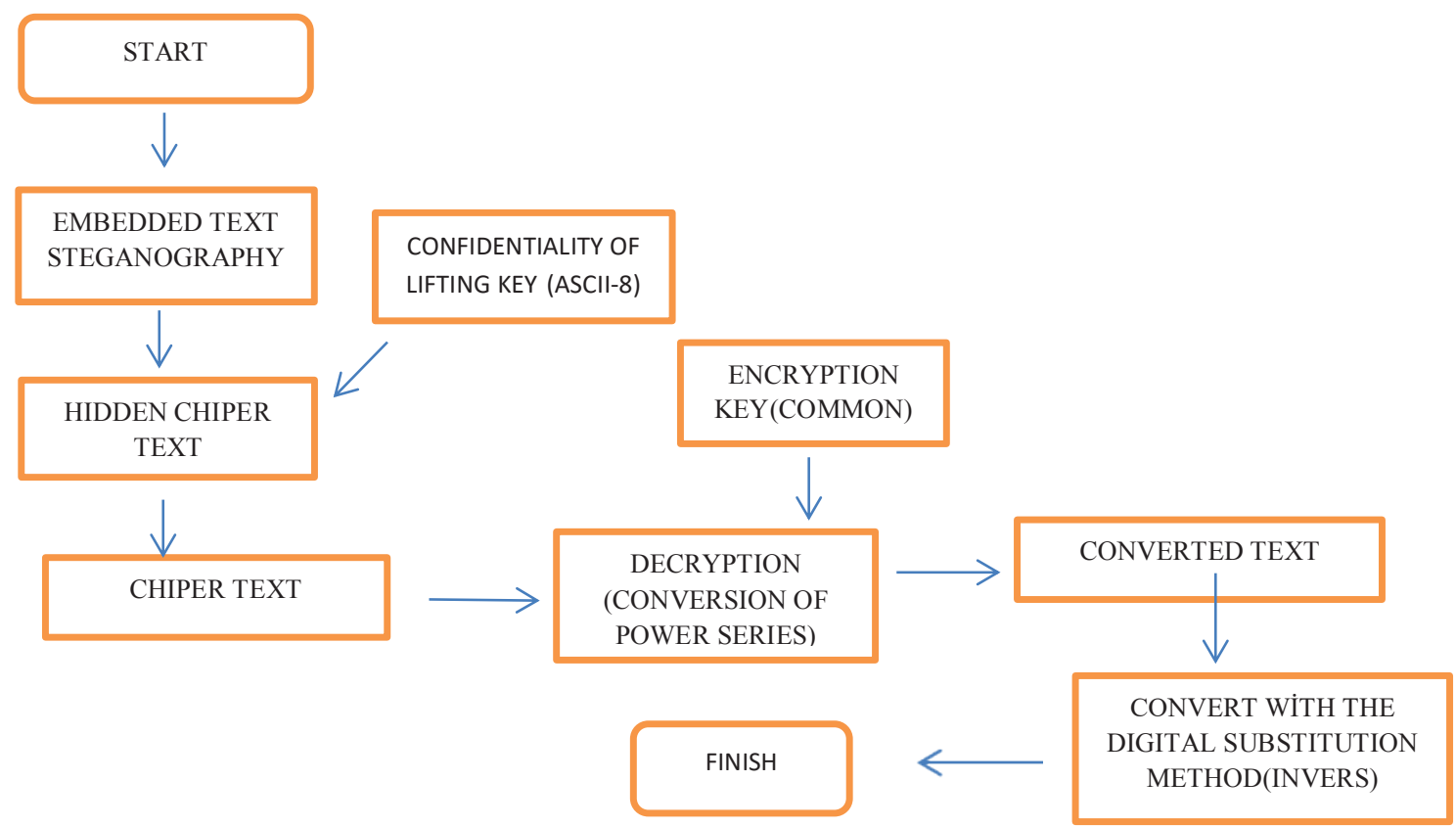

Fig. 3. Flow Diagram of Decryption System 


\section{Remark}

If we expand the Laplace transformation with different values $t, t^{2}, \ldots$ we will get different encrypted texts.

\section{Conclusion}

By using a conversion which we called the power series conversion algorithm has been created.The keys generated using this algorithm is similar to the method known as substitution method in literatüre.But this method has been obtained by the method emerged as a result of digitization.In order to provide greater security developed a hybrid model using steganography and explained the details of it.Through this proposed hybrid model user has hidden this message with keys instead of $\left(K_{n}^{\prime}\right)$ coefficient of $q_{n}$ coefficient obtained by taking and has hidden existence of this message with ASCII code. Then,using another a password is hidden encrypted text into a text.In this way, higher safety feature is provided to data using steganography approach.

\section{References}

1. M.Aydın, G. Gökmen,B. Kuryel, G. Gündüz, Diferansiyel Denklemler ve Uygulamaları, Barış Yayınları, (1990)

2. Koç,C.K., Cryptographic Engineering, Springer, (2009),

3. Belgacem,F.B.M.,Karaballi,A.A.,Kalla,L.S. Analytical Investigations of the Sumudu Transform and Applications to Integral Productions Equations,Mathematical Problems in Engineering, 3, 103-118 (2003)

4. Gençoğlu,M.T., Use of Integral Transform in Cryptology.Science and Eng. J of Frrat Univ. 28(2), $217-$ 220 (2016)

5. https://tr.wikipedia.org/wiki/ASCII

6. Martin,K.M., Everyday Cryptography Fundemental Principles and Applications, Oxford University Press. (2012)

7. Delfs,H.,Knebl,H.,Introduction to Cryptography Principles and Applications, Springer, (2007)

8. Yalman,Y.,Ertürk,İ. Kişisel Bilgi Güvenliğnin Sağlanmasında Steganografi Bilminin Kullanımı. ÜNAK (2009)

9. Paar,C.,Pelzl,J., Understanding Cryptography, Springer, (2010)

10. S. Usha, G. A. Sathish Kumal, K. Boopathybagan., A. Secure Triple Level Encryption Method UsingCryptography and Steganography. International Conference on Computer Science and NetworkTechnology, IEEE. (2011)

11. Johnson, N.F. ve Jajodia, S.,Exploring steganography: Seeing the unseen, Computer, 31( 2), 26-34 (1998) 